Marquette University

e-Publications@Marquette

Physical Therapy Faculty Research and Publications

Physical Therapy, Department of

$3-2015$

\title{
A Teaching Tool to Visually Illustrate How Manipulating the Physiology of the Ventilatory Muscle Pump Alters Functional Performance
}

Dennis Sobush

Marquette University, dennis.sobush@marquette.edu

Follow this and additional works at: https://epublications.marquette.edu/phys_therapy_fac

Part of the Physical Therapy Commons

\section{Recommended Citation}

Sobush, Dennis, "A Teaching Tool to Visually Illustrate How Manipulating the Physiology of the Ventilatory Muscle Pump Alters Functional Performance" (2015). Physical Therapy Faculty Research and

Publications. 86.

https://epublications.marquette.edu/phys_therapy_fac/86 
Marquette University

e-Publications@Marquette

\title{
Physical Therapy Faculty Research and Publications/College of Health Sciences
}

This paper is NOT THE PUBLISHED VERSION; but the author's final, peer-reviewed manuscript. The published version may be accessed by following the link in the citation below.

Cardiopulmonary Physical Therapy Journal, Vol. 26, No. 1 (March 2015): 22-25. DOI. This article is (C) Wolters Kluwer and permission has been granted for this version to appear in e-

Publications@Marquette. Wolters Kluwer does not grant permission for this article to be further copied/distributed or hosted elsewhere without the express permission from Wolters Kluwer.

\section{A Teaching Tool to Visually Illustrate How Manipulating the Physiology of the Ventilatory Muscle Pump Alters Functional Performance}

\author{
Dennis C. Sobush
}

Department of Physical Therapy, Marquette University, Milwaukee, WI

Acute Rehabilitation Services-Froedtert Memorial Lutheran Hospital, Milwaukee, WI

\section{Abstract}

This clinical perspective article describes an inexpensive pedagogical tool intended for use in a laboratory setting as part of a cardiovascular and pulmonary physical therapy course. It uses a dual balance scale schematic/model. As a teaching resource, physical therapy students can use it to visually reinforce their understanding of the complex cause-and-effect interplay between physiological factors 
that affect ventilatory muscle pump (VMP) performance for sustained breathing or contribute to VMP fatigue/failure.

The purpose of this clinical perspective article is to describe an inexpensive pedagogical tool intended for use in a laboratory setting as part of a cardiovascular and pulmonary physical therapy course. Based on a dual balance scale schematic/model published by Vassilakopoulos, et al, ${ }^{1}$ physical therapy students can visually reinforce their understanding of the complex cause-and-effect interplay between physiological factors that affect ventilatory muscle pump (VMP) performance for sustained breathing as opposed to fatigue/failure.

\section{DESCRIPTION OF THE MODEL}

This teaching tool can be constructed at a cost of approximately $\$ 30$. Materials included 4 plastic hollow rigid tubes, 2 bolts, 2 wing nuts, 2 rubber washers, 1 flexible interconnecting tube fixed by 4 circumferential clamps, 2 wooden bases, 2 hooks each of a different color, 2 square plastic holders, and 12 plastic containers ( 3 each of 4 different colors filled to different amounts with colored gravel used in aquariums). In addition, it folds up for portability and is lightweight.

The muscles of the VMP have the unique characteristic of being under both voluntary (eg. as in singing) and involuntary (eg, during sleep) control. However, like all muscles that are skeletal (ie, striated) in nature, the muscles that govern the VMP predictably respond according to fundamental physiological principles that include contractile force capacity regulated by length-tension relationships (eg, increased maximal inspiratory pressure at near residual volume as opposed to near total lung capacity) $^{2}$; a training response of increased strength when an overload stimulus is applied (eg, threshold inspiratory muscle training $)^{3,4}$ and conversely to deconditioning or disuse (eg, prolonged use

of control mode mechanical ventilation) ${ }^{5}$; generating movement for function (eg, costal fibers of the diaphragm on the rib cage for increasing lateral costal expansion) ${ }^{6}$; percentage composition of type I slow-oxidative versus type II fast-glycolytic fibers that favor contractile endurance (eg, an infant in the first year of life being prone to diaphragmatic fatigue due to having fewer type I oxidative fibers than the adult) ${ }^{7}$; and contractile behavior that can be concentric (eg, shortening of the diaphragm as in taking a breath), ${ }^{8}$ eccentric (eg, lengthening of the diaphragm as in phonation/speech), ${ }^{9,10}$ or isometric (eg, stabilization of the diaphragm to produce intra-abdominal pressure during a lift performed by the upper extremities). ${ }^{11}$

Physical therapists use the Guide to Physical Therapist Practice ${ }^{12}$ to design and implement plans of care for patients. Those who are classified into the Cardiovascular/Pulmonary preferred practice patterns may demonstrate functional compromise due to "Impaired Ventilation and Respiration/Gas Exchange Associated with Ventilatory Pump Dysfunction or Failure" (pattern E). ${ }^{12}$ Patients diagnosed to fall within this category do not have adequate VMP and gas exchange to meet the oxygen demands at rest, during aerobic exercise, and during the performance of activities of daily living.

Numerous diseases (eg, amyotrophic lateral sclerosis) and conditions (eg, diaphragmatic paralysis) have, as a final common pathway, VMP dysfunction/failure resulting in respiratory fatigue and/or failure. In a worst case scenario, death will ensue unless ventilation is sustained by artificial means. Fortunately, multiple physiological factors can be manipulated to circumvent VMP fatigue and avoid resultant respiratory failure. Organizing these factors according to 2 discrete balance scales, one 
representing VMP endurance (ie, energy supplies balanced by energy demands) and the other representing neurocardiorespiratory capacity (ie, load per breath balanced by neuromuscular competence), is clinically beneficial for planning treatment intervention strategies. Interconnecting these 2 balance scales affords an even greater appreciation of the interplay between these factors as Figures 1-3 serve to illustrate.

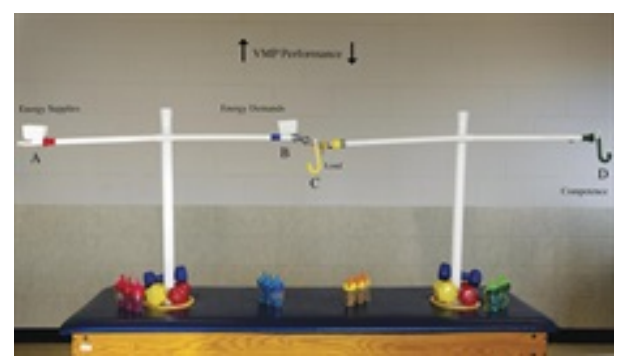

Fig. 1: Dual balance scale model of the ventilatory muscle pump (VMP) in a relative state for sustained functional performance. A, energy supplies; B, energy demands; C, load per breath; D, neuromuscular competence.

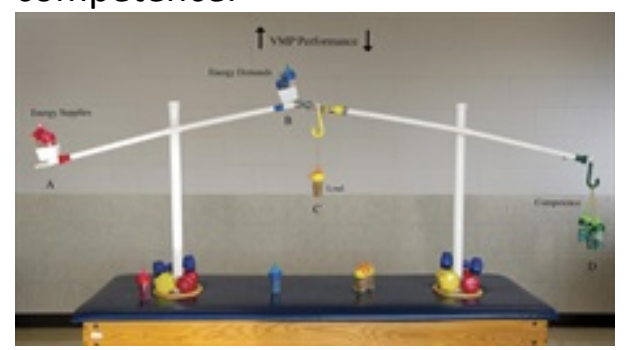

Fig. 2: Dual balance scale model favoring ventilatory muscle pump (VMP) sustained breathing to avoid fatigue/failure. Note the high energy supplies (A) and neuromuscular competence (D). $B$, energy demands; D, neuromuscular competence.

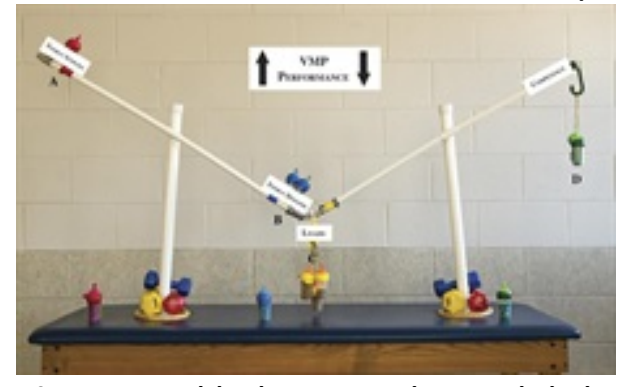

Fig. 3: Dual balance scale model showing factors prone to ventilatory muscle pump (VMP) fatigue/failure. Note increased load per breath (C) and decreased neuromuscular competence (D). A, energy supplies; B, energy demands.

The left balance scale lever arms A and B in Figure 1 represent a balance between "energy supplies" and "energy demands," respectively. Energy supplies $(A)$ that are adequate for the VMP to sustain spontaneous breathing include the blood flow to the inspiratory muscles, the blood substrate that fuels the contractile process, arterial oxygen content, the muscle's uptake ability to use the energy sources, and the muscle's energy stores. Energy demands (B) are also multifactorial and include the fraction of the inspiratory muscle pressure for tidal breathing (PI) to the maximum inspiratory pressure (PImax) that the inspiratory muscles can generate (PI/PImax); the minute ventilation $\left(\mathrm{V}_{\mathrm{E}}\right)$; the inspiratory duty cycle, defined as the fraction of inspiration to the total breathing cycle duration $\left(\mathrm{tl} / \mathrm{t}_{\text {total }}\right)$; and the mean inspiratory flow rate $(\mathrm{VT} / \mathrm{tl})$. Under normal conditions at rest, a large energy 
supply reserve exists and the energy demands favor VMP performance efficiency without the onset of contractile fatigue. In Figure 1, the left scale looks to be "balanced" such that energy supplies are sufficient to meet the energy demands.

The balance scale on the right in Figure 1 has lever arms C and D that represent "load per breath" and "neuromuscular competence," respectively. The inspiratory muscles of the VMP must be able to generate enough force to inflate the lungs by overcoming the elastance loads (C) imposed by both the lungs and chest wall, breath by breath. In addition, resistive loads of airflow through the airways and tissues must also be accounted for to permit adequate ventilation. The degree to which the VMP can sustain contractile performance (ie, endurance) without succumbing to fatigue/failure will also depend on the loads per breath that can be counterbalanced by the neuromuscular competence of the VMP to meet the demands placed on it. As the interconnected dual scales in Figure 1 suggest, the VMP is in a relative state of balance for sustained ventilation.

Figure 2 represents factors needing to be manipulated in favor of increasing VMP performance. A hypothetical clinical scenario that is plausible might be a patient in severe right diastolic congestive heart failure that is further complicated by increased loads per breath (C) due to ascites and pulmonary edema; decreased neuromuscular competence (D) secondary to deconditioning and electrolyte depletion from diuretic medication; compromised energy supplies (A) related to dyspnea and poor tolerance for nutritional intake; and increased energy demands (B) in this patient who experiences frequent panic attacks. Intervention for enhancing VMP performance in this patient example might include adding weights to $D$ by normalizing electrolytes and providing resistive inspiratory muscle training; removing weights from $\mathrm{C}$ to represent judicious management of fluids; adding weights to $\mathrm{A}$ by administering supplemental oxygen and providing more frequent meals in smaller quantities but high in protein and calories; and removing weights from $B$ to represent the use of a mild sedative and the practice of deep breathing and relaxation exercises.

In contrast, Figure 3 might represent a mechanically ventilated patient with an exacerbation of chronic bronchitis complicated by pneumonia. Medical treatment efforts to increase A (eg, supplemental caloric intake) and enhancing $\mathrm{D}$ (eg, by changing the ventilator setting to assist control and/or reducing the sedation) is not enough to offset $B$ (eg, the energy demand of a fever) and C (eg, the increased load per breath due to excessive secretions and atelectasis). Unless the treatment plan for this case scenario is adjusted to provide the appropriate antibiotic and remove the obstructing secretions, function of the VMP may not be adequate for extubation due to the inability to sustain performance without fatiguing (eg, failing a spontaneous breathing trial).

\section{SUMMARY}

The interconnected dual balance scale device has been used in a cardiovascular/pulmonary physical therapy laboratory course. Students can manipulate one or more factors by applying and/or removing weights to the corresponding balance scale location. By doing so, students can test their individual hypotheses for generating a predictable functional outcome trend of whether the VMP can sustain breathing or will succumb to fatigue/failure. 


\section{REFERENCES}

1. Vassilakopoulos T, Zakynthinos S, Roussos Ch. Respiratory muscles and weaning failure. Eur Respir J. 1996;9(11):2383-2400.

2. Evans JA, Whitelaw WA. The assessment of maximal respiratory mouth pressures in adults. Respir Care. 2009;54(10):1348-1359.

3. Smart NA, Giallauria F, Dieberg G. Efficacy of inspiratory muscle training in chronic heart failure patients: A systematic review and meta-analysis. Int J Cardiol. 2013;167(4):1502-1507.

4. Martin AD, Smith BK, Davenport PD, et al.. Inspiratory muscle strength training improves weaning outcome in failure to wean patients: A randomized trial. Crit Care. 2011;15(2):R84.

5. Gayan-Ramierz G, Decramer M. Effects of mechanical ventilation on diaphragm function and biology. Eur Respir J. 2002;20(6):1579-1586.

6. Estenne M, Yernault JC, DeTroyer A. Rib cage and diaphragm-abdomen compliance in humans: Effects of age and posture. J Appl Physiol. 1985;59(6):1842-1848.

7. Gaultier C. Respiratory muscle function in infants. Eur Respir J. 1995;8(1):150-153.

8. Boynton BR, Barnas GM, Dadmun JT, et al.. Mechanical coupling of the rib cage, abdomen, and diaphragm through their area of apposition. J Appl Physiol. 1991;70(3):1235-1244.

9. Hixon TJ, Mead J, Goldman MD. Dynamics of the chest wall during speech production: Function of the thorax, rib cage, diaphragm, and abdomen. J Speech Hear Res. 1976;19(2):297-356.

10. Leanderson R, Sundberg J, von Euler C. Role of diaphragmatic activity during singing: A study of transdiaphragmatic pressures. J Appl Physiol (1985). 1987;62(1):259-270.

11. Kolar P, Sulc J, Kyncl M, et al.. Stabilizing function of the diaphragm: Dynamic MRI and synchronized spirometric assessment. J Appl Physiol (1985). 2010;109(4):1064-1071.

12. American Physical Therapy Association. Guide to physical therapist practice second edition. Phys Ther. 2001;81(1):9-744.

\section{Keywords:}

failure, fatigue; ventilatory muscle performance 